\title{
Group decision making process for early stage evaluations of infrastructure projects using extended VIKOR method under fuzzy environment
}

\author{
Ivan Belošević * D, Milana Kosijer, Miloš Ivić and Norbert Pavlović
}

\begin{abstract}
Purpose: This paper considers the evaluations of project alternatives at the early stages of infrastructure project developments. Although it is expected to make important decisions at project early stages, it is rarely possible to obtain reliable data for exact evaluations. To deal with low quality data and the existence of uncertainties, this paper extends the evaluation problem to the fuzzy environment.
\end{abstract}

Methods: We propose group decision making process for early stage evaluations of infrastructure projects. The evaluation approach utilizes combination weighting and compromise ranking. We integrate subjective and objective weighting methods to specify criteria weights. Afterwards, we use the VIKOR method to rank alternatives in the presence of conflicting criteria.

Results: As a case study, we illustrate the evaluation problem within a railway line reconstruction project. Specifically, the proposed approach is efficiently applied to evaluate and rank several route alternatives considered within the reconstruction project of the regional line Pančevo - Vršac at Serbian railway network.

Conclusions: The provided example illustrates the applicability of the proposed approach to deal with the evaluations at the early stage of the railway line reconstruction. The existence of uncertainties at early stages of project developments is common, so the proposed method is also applicable for other linear infrastructure in transport sector.

Keywords: Multi-criteria analysis, Group decision making, Aggregation of expert opinions, fuzz VIKOR, Project evaluation, Transportation infrastructure

\section{Highlights}

- Group decision making process is proposed for evaluations of infrastructure projects.

- The paper deals with the uncertainties present at the early stage of project developments.

- A novel evaluation approach utilizes combination weighting and compromise ranking.

- Subjective and objective weighting methods are integrated to specify criteria weights.

- VIKOR method extended under fuzzy environment is used to rank project alternatives.

* Correspondence: i.belosevic@sf.bg.ac.rs

University of Belgrade - Faculty of Transport and Traffic Engineering, Vojvode Stepe 305, Belgrade 11000, Serbia
- The approach is tested within the real-world project of railway line reconstruction.

\section{Introduction}

A large number of project evaluations and selections have to be made during the life cycle of transportation infrastructure. The evaluations and selections are required in the entire period starting with planning and design, construction, operation and finally displacement stages. In order to make appropriate decisions, project evaluations have to extend standard financial considerations with various socio-economic aspects related to external costs, sustainability, spatial and environmental impacts. Therefore, a formal approach known as Multi-Criteria Decision Making $(\mathrm{MCDM})$ is commonly adopted, so that open and 
transparent decisions can be made. MCDM strives to evaluate infrastructure alternatives considering all aforementioned issues as a combination of multi-dimensional and often conflicting criteria.

In the present literature on planning and design of linear transportation infrastructure, a variety of MCDM methods has been applied to address route evaluations and selection decisions [1-3]. Although the related literature demonstrates the general applicability of the MCDM approach, the problem of evaluating alternatives under uncertainty has not received sufficient attention from researchers so far. In order to fill this knowledge gap, we consider the problem of decision making under uncertainty addressing the early stage project evaluation.

At the early stage, draft route alternatives should be evaluated in order to ensure a sound conceptual solution as a framework for further detailed project considerations. Although it is expected to make important decisions, it is rarely possible to obtain reliable data for exact evaluations. Due to a low budget, tight schedule or other limited resources, conceptual alternatives cannot be generated and evaluated in details. Instead, the alternatives are roughly designed providing quite a poor base for making decisions. Therefore, we propose a MCDM approach under uncertainty as a more appropriate approach for the early stage project evaluation rather than adopting existing models that require complete information, mostly unattainable at this stage of project development. In contrast to the present literature, the main contributions and innovative features of this paper are as follows.

Firstly, the paper develops a novel model for the early stage project evaluation combining VIKOR method and fuzzy sets theory. The model is based on linguistic variables and evaluates infrastructure alternatives in the presence of both quantitative and qualitative criteria efficiently. The paper extends the evaluation problem to a Group Decision Making (GDM) environment. The proposed approach allows aggregating individual expert opinions, coming from different professional fields, into a single collective expertise.

Secondly, the paper determines criteria weights integrating subjective and objective weighting methods. The combined weighting has been applied in decision making literature [4-6], however it has never been applied regarding the project evaluation. Subjective weighting leans on decision maker's judgment, while objective weighting leans on strict mathematical calculations performed over ratings of alternatives. The influence of decision maker's judgment regarding the evaluation criteria is, thus, excluded.

Finally, this paper adopts a combined set of quantitative and qualitative criteria applicable for railway infrastructure and employs a real-world case study to illustrate the proposed model for the project evaluation. Specifically, the case study presents the early stage evaluation of a railway line reconstruction project. The model is applied to rank four alternative routes of the regional line Pančevo - Vršac at Serbian railway network. In order to take a step ahead from standard case study exercises, we provide a deeper analysis of the aggregation results comparing them with the results based on individual judgments of decision makers. Also, we analyse the stability of ranking results differing values of two important model parameters that reflect the applied decision making and criteria weighting strategies.

The rest of the paper is structured as follows. Section 3 reviews the literature on planning and design of linear transportation infrastructure and identifies knowledge gaps. Section 4 presents preliminary definitions of fuzzy sets theory, Shannon entropy and VIKOR method. Section 5 determines the proposed framework for the evaluation of infrastructure projects. The case study is provided in Section 6 and concluding remarks are summarized in Section 7.

\section{Literature review}

\subsection{Related work}

During the past two decades, a number of papers has concerned the problem of planning and design of transportation infrastructure applying multi-criteria evaluations. A comprehensive review on the use of MCDM methods could be found in [7] or as a part of recent surveys on the assessment tools in civil and infrastructure engineering [8-10].

The most frequently used method is Analytic Hierarchy Process (AHP). Intending to facilitate transport infrastructure planning, Kalamaras et al. [1] used AHP method for the problem of highway route selection. Criteria were defined following principal objectives to maximize operation functionality and project economics, as well as to minimize construction problems and environmental impacts. The paper presented a case study considering five highway alternatives from South America. In the same manner, the AHP method was used by Banai [11] to facilitate public transportation decision making. As a case study, the paper evaluated light rail transit (LRT) corridor and route alternatives in Memphis, Tennessee. The same author contributed in further development of the methodology for multi-criteria evaluation of transportation infrastructure applying Analytic Network Process (ANP), as a nonlinear form of AHP [12]. As a case study, the paper examined the aforementioned case of Memphis LRT system drawing attention to the site-specific lend use criteria. 
In addition to the AHP method, different methods were also conducted for the evaluation of linear infrastructure. Compromise programming techniques were used by Ballestero et al. [13] and Kosijer et al. [2]. Ballestero et al. [13] developed a Bayesian decision model based on utility maximisation as a standard methodology to evaluate alternatives under non-strict uncertainty. The utility function was estimated objectively applying market-based social weighting. Probabilistic values for states of nature were subjectively determined based on interviews with decision makers. Five alternatives of a ring-road in Madrid metropolitan area were evaluated based on three cost criteria (investment costs, right of way costs, external costs of noise pollution) and two benefit criteria (savings in travelling costs and gains in real estates). Kosijer et al. [2] proposed a methodology for railway route planning and design based on multi-criteria decision making. As a case study, the VIKOR method was applied for ranking four railway route alternatives on the Pan-European Corridor X through Serbia. The alternatives were evaluated among three quantitative criteria (investments, operation costs and capacity) and two qualitative criteria (impacts on spatial development and environment). Anton and Grau [14] and Saat and Aguilar [15] investigated the use of the ELECTRE method providing an alternative selection of high speed rail (HSR) lines. Anton and Grau [14] focused on the Spain HSR network analysing the line between Madrid and Valencia as a case study. They evaluated three route alternatives using four standard criteria (investments, travel time, potential users and environmental impacts). Similarly, Saat and Aguilar [15] focused their research on the HSR development in Malaysia partly changing the set of criteria. Three route alternatives were evaluated using three criteria based on the following indicators: investments, total population and gross domestic product. Sperry et al. [3] developed a model based on weighted sum approach as a part of methodology for the evaluation of HSR lines. The proposed model was applied on the case study of railway network in Texas considering 13 alternative routes to connect two existing HSR corridors. The multi-criteria assessment of projects in transport sector applying weighting methods was also conducted by Delle Site and Fillippi [16]. Authors compared three methods within the multi-attribute value theory (MAVT): ratio with swings, Saaty scale with swings, and trade-off. In addition to the theoretical considerations on correlations among these methods, authors provided suggestions how MAVT should be applied to transport projects highlighting the differences among various weighting methods.

Multi-criteria assessment of infrastructure design projects in transport sector was addressed in e.g.
Brauers et al. [17] and Barić et al. [18]. The papers considered the evaluation process of road design alternatives applying MOORA and AHP methods, respectively. Sarrazin and De Smet [19] improved the road design evaluation emphasizing the safety performances. The case study concerned the reconstruction of a secondary road in a rural area. The authors defined ten draft alternatives and evaluated them applying the PROMETHEE method. Additionally, the integration of a multi-criteria decision analysis as a part of methodologies for assessing road safety measures was also proposed in [20-22].

\subsection{Knowledge gap}

The present literature has focused on identifying the most important criteria and indicators, as well as on explaining the main steps of various MCDM methods applied for planning and design of linear transportation infrastructure. The majority of the literature utilizes MCDM methods taking deterministic values on preferences of route alternatives conducted among mostly quantitative criteria. Only a few papers (e.g. Ballestero et al. [12]) considers the project evaluation under uncertainty. In fact, the problem is simplified as it neglects the uncertainty issues that in reality affect infrastructure projects. These uncertainty issues commonly refer to different limited resources, lack of information or uncertain project outputs.

In contrast to the aforementioned papers, this paper formulates the early stage project evaluation as a GDM process and proposes the VIKOR method to rank project alternatives under fuzzy environment. In the proposed model, a committee of professional experts assesses project alternatives in linguistic variables relying on their own knowledge and experiences.

\section{Preliminary definitions}

\subsection{Fuzzy set theory and linguistic variables}

Fuzzy set theory was developed by Zadeh [23] as a conceptual framework to treat uncertain and imprecise situations existing in the real life. Incorporating fuzzy set theory in the MCDM methodology, Bellman and Zadeh [24] introduced a mathematically precise way of treating vagueness and subjectivity in assigning criteria weights and performance rating of each alternative regarding evaluation criteria. So far, various MCDM methods have been extended under fuzzy environment and applied in different fields of engineering or management [25-27]. In this paper, we involve the application of fuzzy logic and VIKOR method focusing on early stage evaluations of infrastructure projects.

For the sake of simplicity, we utilize triangular fuzzy numbers to represent linguistic variables in this paper. In the literature $[28,29]$, a triangular fuzzy 


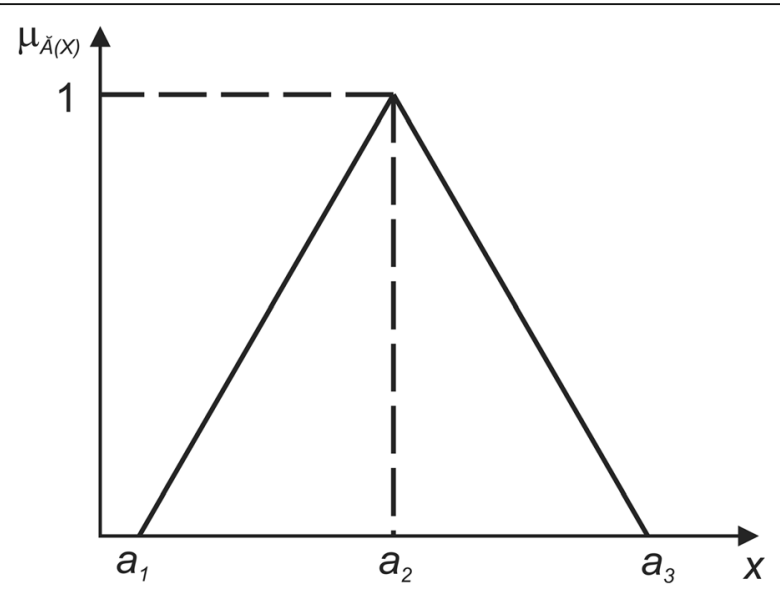

Fig. 1 Triangular fuzzy number

number $\tilde{A}=\left(a_{1}, a_{2}, a_{3}\right)$ is determined as a triplet of crisp numbers such that $a_{1}<a_{2}<a_{3}$ (see Fig. 1). The function value $\mu_{\tilde{A}}(x)$ stands for the membership degree of $x$ in $\tilde{A}$, such that a higher $\mu_{\tilde{A}}(x)$ means a higher degree of belongingness for $x$ in $\tilde{A}$. Main algebraic operations on fuzzy numbers are presented and discussed in detail in the existing literature [30, 31].

$$
\mu_{\tilde{A}}(x)=\left\{\begin{array}{c}
0, x<a_{1} \\
\left(x-a_{1}\right) /\left(a_{2}-a_{1}\right), a_{1}<x<a_{2} \\
\left(a_{3}-x\right) /\left(a_{3}-a_{2}\right), a_{2}<x<a_{3} \\
0, x>a_{3}
\end{array}\right\}
$$

According to Chen [32], the distance between two triangular fuzzy numbers $\tilde{A}=\left(a_{1}, a_{2}, a_{3}\right)$ and $\tilde{B}=\left(b_{1}, b_{2}\right.$, $\left.b_{3}\right)$ can be derived utilizing the Vertex method (1).
Although the crisp value of triangular fuzzy number can be derived utilizing different defuzzification methods, we apply the Centoid method in this paper (2).

$$
\begin{aligned}
& d(\tilde{A}, \tilde{B})=\sqrt{\left[\left(a_{1}-b_{1}\right)^{2}+\left(a_{2}-b_{2}\right)^{2}+\left(a_{3}-b_{3}\right)^{2} / 3\right]} \\
& x_{0}(\tilde{A})=\left(a_{1}+a_{2}+a_{3}\right) / 3
\end{aligned}
$$

Within a decision making process, experts often tend to use linguistic variables to accommodate fuzziness contained in their judgments. The following sets of linguistic terms with their corresponding triangular fuzzy numbers (see Figs. 2 and 3) are adopted to express values of linguistic variables in order to evaluate criteria weights and ratings of alternatives.

\subsection{Entropy concept}

As we previously mentioned, we integrate subjective and objective weighting, as two divergent approaches, in order to determine criteria weights. In contrast to subjective weighting that leans on decision maker's judgment, objective weighting leans on strict mathematical calculations performed over ratings of alternatives. In that sense, weights are obtained indirectly excluding the influence of decision maker's judgment regarding the specific criteria. In the recent literature [4-6, 33, 34], the Shannon's Entropy concept [35] has been commonly used for deriving the objective weights of criteria. Entropy concept can be concisely presented through the following steps:

Step 1: Normalize the decision matrix and calculate projected outcomes as follows:

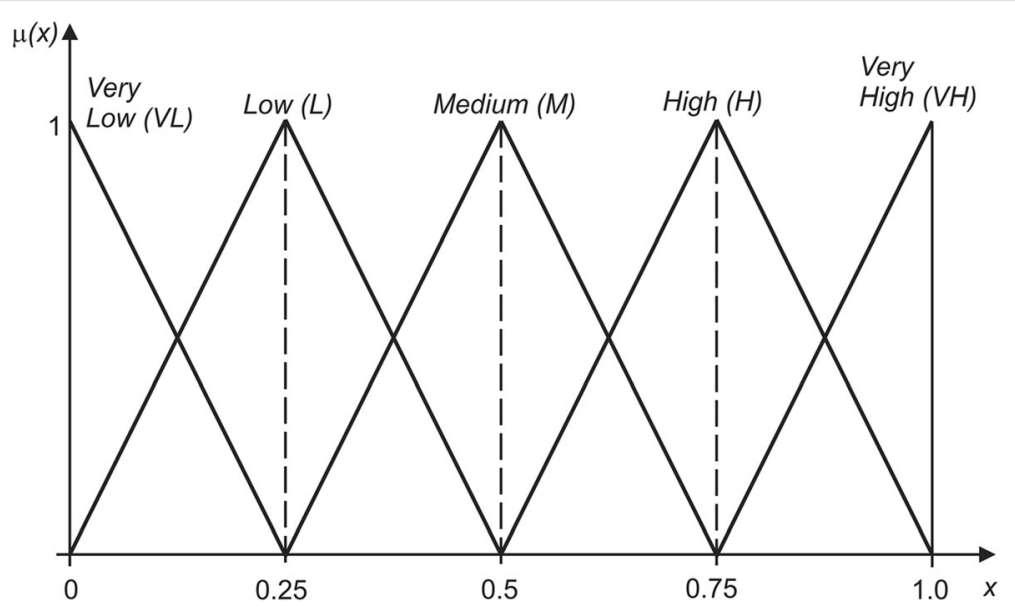

Fig. 2 Linguistic variable of criteria weights 


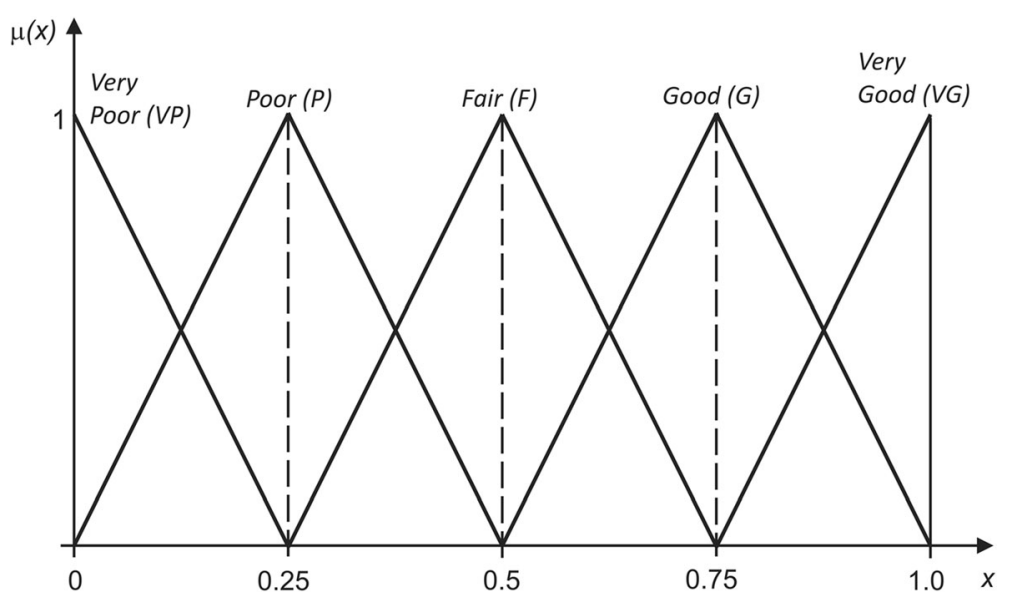

Fig. 3 Linguistic variable of alternative ratings

$$
P_{i j}=x_{i j} / \sum_{i=1}^{m} x_{i j} i=1, \ldots, m, j=1, \ldots, n
$$

Step 2: Calculate the entropy of attribute $j$ using the following equation:

$$
e_{j}=-k \sum_{i=1}^{m} P_{i j} \ln \left(P_{i j}\right) \quad j=1, \ldots, n
$$

where $k$ stands for the entropy constant and is equal to $1 / \ln (m)$.

Step 3: Define the degree of divergence:

$$
d_{j}=1-e_{j}
$$

Step 4: Obtain the entropy weight of attribute $i$ as follows:

$$
w_{j}=d_{j} / \sum_{j=1}^{n} d_{j} j=1, \ldots, n
$$

The entropy weight represents the degree of divergence between alternatives concerning a certain criterion. The greater entropy value causes the lower degree of divergence between alternatives concerning the same criterion. It makes the entropy weight smaller, thus affecting the importance of this criterion in a decision process.

\subsection{VIKOR method}

The VIKOR method was developed by Opricović [36] and since then numerous scientific papers have demonstrated its applicability to solve decision making problems with conflicting criteria [37]. The theoretical background of the VIKOR method has been extensively investigated and discussed in the literature [38, 39]. Finally, the recent state of the art of the VIKOR method has exposed the rapid growth in the use of this technique both among researchers and practitioners $[40,41]$.

The VIKOR method ranks a set of alternatives and selects a compromise solution (one or a subset of alternatives) as a solution closest to the ideal. Specifically, the measure of "closeness" aggregates individual regrets that the ideal cannot be achieved (see Eq. 7). The $L^{p}$ cregret for a decision [42-44].

$$
L_{i}^{p}=\left\{\sum_{j=1}^{n}\left[w_{j}\left(f_{j}^{*}-f_{i j}\right) /\left(f_{j}^{*}-f_{j}^{-}\right)\right]^{p}\right\}^{1 / p} \quad 1 \leq p \leq \infty, i=1, \ldots, m
$$

where $m$ is the number of feasible alternatives $A_{i}(i=1$, $\ldots, m) ; f_{i j}$ is the value of the $j^{\text {th }}$ criterion function for alternative $A_{i} ; f_{j}^{*}$ and $f_{j}^{-}$are the best and the worst values of the $j^{\text {th }}$ criterion function, respectively; and $w_{j}(j=1, \ldots$, $n$ ) are weighting coefficients (weights).

In the VIKOR method, $S_{i}$ and $R_{i}$ stand for ranking measures (see Eq. 8 and Eq. 9). The measure $S_{i}$ (as the lower boundary $L_{i}^{1}$ in Eq. 7) simply turns the $L^{p}$ function into the linear form and sums all individualregrets. Particularly, the solution obtained minimizing $S_{i}$ provides "a maximum group utility". On the other hand, the measure $R_{i}$ (as the upper bound $L_{i}^{\infty}$ in Eq. 7) returns the maximal individual regret and therefore the solution obtained minimizing $R_{i}$ provides "a minimum individual regret of the opponent". 


$$
\begin{aligned}
& S_{i}=\sum_{j=1}^{n} w_{j}\left(f_{j}^{*}-f_{i j}\right) /\left(f_{j}^{*}-f_{j}^{-}\right) \\
& R_{i}=\max _{j}\left[w_{j}\left(f_{j}^{*}-f_{i j}\right) /\left(f_{j}^{*}-f_{j}^{-}\right)\right]
\end{aligned}
$$

The main compromise ranking measure $Q_{i}$ aggregates $S_{i}$ and $R_{i}$ providing a balance between these two divergent ranking measures:

$$
\begin{aligned}
Q_{i}= & v\left(S_{i}-S^{*}\right) /\left(S^{-}-S^{*}\right)+(1-v) \\
& \times\left(R_{i}-R^{*}\right) /\left(R^{-}-R^{*}\right)
\end{aligned}
$$

where $\quad S^{-}=\max S_{i}, S *=\min S_{i}, R^{-}=\max R_{i}, R *$ $=\min R_{i}$ and $v \in[0,1]$. The parameter $v$ is introduced as the weight of the decision making strategy.

\section{The proposed method}

The proposed method for the early stage evaluation of transport infrastructure will be described in the context of a railway line reconstruction project. Considering basic fuzzy logic, Entropy and VIKOR principles, the proposed framework for an assessment of railway route alternatives could be deployed as shown in Fig. 4.
Suppose that an assessment of railway route alternatives is considered as a GDM process with $\mathrm{K}$ decision makers $D M_{k}(k=1,2, \ldots, K)$ that evaluate a set of $m$ alternatives $A_{i}(i=1,2, \ldots, m)$ with respect to $n$ criteria $C_{j}(j$ $=1,2, \ldots, n)$. Relying on the concept of existing procedures used to handle GDM under fuzzy environment [33, 45-47], the main steps of the proposed approach for the early stage evaluation of transport infrastructure are summarized as follows.

Step 1: Define the problem scope.

The first step in decision making process is to gather relevant information in order to identify the problem scope. The general aim of this paper is to evaluate and select a favourable railway route from a set of draft route alternatives at the project early stage. In particular, railway lines, as complex infrastructural objects, demand not only huge investments for their construction or reconstruction but also a large amount of work on the project development. Therefore, it is very important to find a suitable draft railway route alternative at the early stage of the project as the conceptual base for further project development and detailed evaluations. The selected

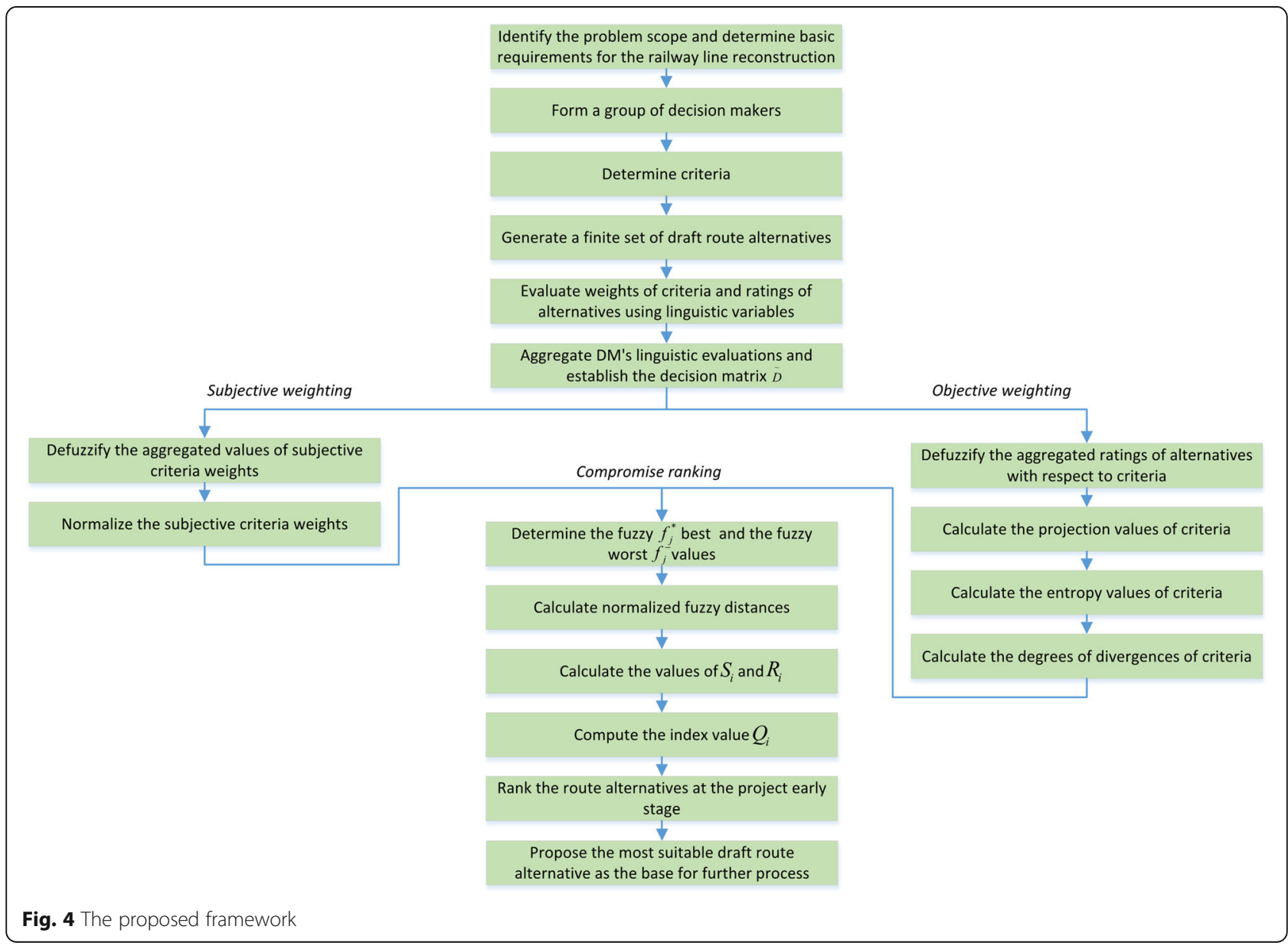


alternative has to make balance between infrastructure investments, transportation service quality, economic benefits and environmental protection on one side and land use restrictions on the other side.

Step 2: Define group decision making attributes. Firstly, it is required to form a decision committee considering the problem scope. Generally various decision makers could be involved in an assessment of railway route alternatives in order to contribute their professional background or expertise in evaluating different aspects, such as structure design, rail traffic design, project economics, risks and impacts.

Afterwards, it is required to identify attributes (criteria and alternatives). The criteria have to be determined considering the objectives defined in the problem scope in order to properly assess potential railway route alternatives. Based on the gathered information at the project early stage, which is mostly low quality data, it is not possible to create a mathematical model for the railway route generation and its optimization. Instead of a mathematical modelling, it is a rather common procedure to design a finite set of alternatives by varying basic technical and operational elements of the route. Afterwards, the railway route alternatives could be aligned and adjusted to existing spatial structures and conditions.

Step 3: Select linguistic variables and corresponding fuzzy numbers.

As we previously mentioned, decision makers use the linguistic variables depicted in Figs. 2 and 3 to assign the weights of evaluation criteria and ratings of alternatives concerning these criteria.

Step 4: Survey decision makers.

Using predefined linguistic variables, decision makers answer the questions regarding the importance of criteria and ratings of alternatives relevant for the observed infrastructural project. The survey of decision makers is a resource for acquiring criteria weights and ratings of alternatives from each decision maker and for aggregating them into the decision matrix.

Suppose that a decision maker $D M_{k}$ uses a linguistic variable with corresponding fuzzy number to weight the criterion $C_{j}$ as $\tilde{w}_{j k}=\left(w_{j k 1}, w_{j k 2}, w_{j k 3}\right)$ and to rate the alternative $A_{i}$ regarding the criterion $C_{\mathrm{j}}$ as $\tilde{x}_{i j k}=\left(x_{i j k 1}, x_{i j k 2}\right.$ ,$\left.x_{i j k 3}\right)$ then fuzzy weights $\tilde{w}_{j}^{s}$ and fuzzy ratings $\tilde{x}_{i j}$ could be aggregated as:

$$
\tilde{w}_{j}^{s}=\left(w_{j 1}^{s}, w_{j 2}^{s}, w_{j 3}^{s}\right)=\left\{\begin{array}{l}
w_{j 1}^{s}=\min _{k} w_{j k 1} \\
w_{j 2}^{s}=\sum_{k=1}^{K} w_{j k 2} / k \\
w_{j 3}^{s}=\max _{k} w_{j k 3}
\end{array}\right.
$$

$$
\tilde{x}_{i j}=\left(x_{i j 1}, x_{i j 2}, x_{i j 3}\right)=\left\{\begin{array}{l}
x_{i j 1}=\min _{k} x_{i j k 1} \\
x_{i j 2}=\sum_{k=1}^{K} w_{i j k 2} / k \\
x_{i j 3}=\max _{k} x_{i j k 3}
\end{array}\right.
$$

Afterwards, the problem can be concisely expressed in the form of the fuzzy decision making matrix:

$$
\tilde{D}=\left[\begin{array}{cccc}
\tilde{w}_{1}^{s} & \tilde{w}_{2}^{s} & \cdots & \tilde{w}_{n}^{s} \\
\tilde{x}_{11} & \tilde{x}_{12} & \cdots & \tilde{x}_{1 n} \\
\tilde{x}_{21} & \tilde{x}_{22} & \cdots & \tilde{x}_{2 n} \\
\vdots & \vdots & \cdots & \vdots \\
\tilde{x}_{m 1} & \tilde{x}_{m 1} & \cdots & \tilde{x}_{m n}
\end{array}\right]
$$

where $\tilde{w}_{j}^{s}$ is the subjective fuzzy weight of criterion $C_{j}$ and $\tilde{x}_{i j}$ is the fuzzy rating of alternative $A_{i}$ with respect to each criterion $C_{j}$.

Step 5: Determine criteria weights.

In this step, we use both subjective weights aggregated from surveys and objective weights derived applying the entropy-based method. The combination weight of criterion $C_{j}$ could be calculated using the following equation:

$$
w_{j}^{c}=\phi w_{j}^{s}+(1-\phi) w_{j}^{o}
$$

where $\phi \in[0,1]$ provides a balance between the subjective $w_{j}^{s}$ and the objective $w_{j}^{o}$ weights. Initially, we set the value of this parameter to 0.5 . Later, we analyze the stability of ranking results changing the parameter value in range $[0,1]$.

Subjective weighting: Based on the surveys of decision makers, the subjective fuzzy weights are derived using Eq. (8). Afterwards, the subjective fuzzy weights are defuzzified using Eq. (2) and normalized using the following equation:

$$
w_{j}^{s}=\tilde{w}_{j}^{s} / \sum_{j=1}^{n} \tilde{w}_{j}^{s}
$$

Objective weighting: Based on the Shannon's entropy, the objective weights are derived as follows. Firstly, the fuzzy ratings of alternatives regarding each criterion are defuzzified using (2) and normalized using (3) to provide the projected outcomes. Afterwards, the entropy of projected outcomes and the degree of divergence for each criterion are computed using Eqs. (4) and (5), respectively. Finally, the objective weights are obtained using Eq. (6).

Step 6: Determine the fuzzy best $f_{j}^{*}$ and the fuzzy worst $f_{j}^{-}$values for each criterion.

$$
f_{j}^{*}=\max _{i} \tilde{x}_{i j}
$$




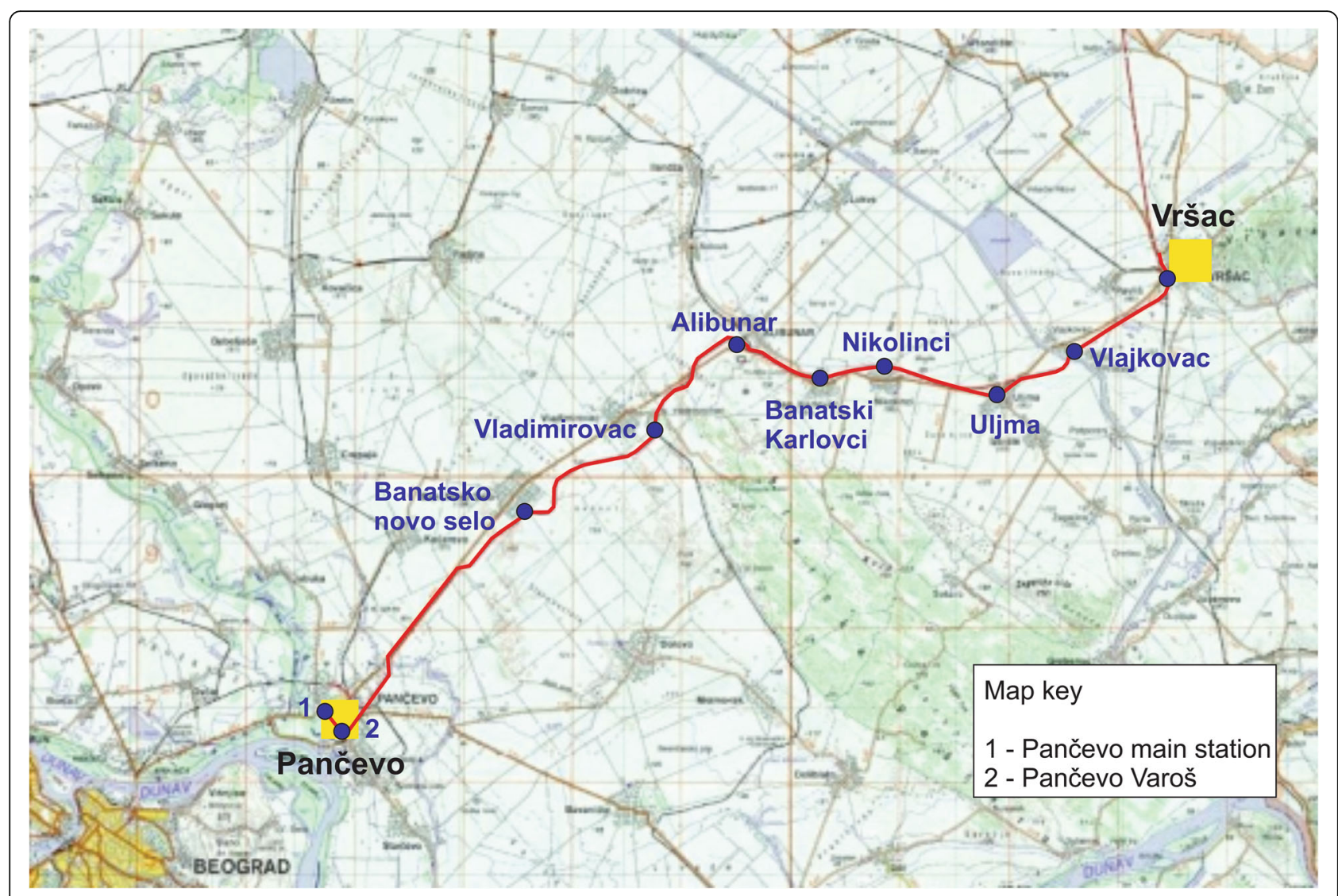

Fig. 5 Railway line Pančevo - Vršac

$$
f_{j}^{-}=\min _{i} \tilde{x}_{i j}
$$

Step 7: Calculate the normalized fuzzy distance $d_{i j}(i=1$, $\ldots m, j=1, \ldots, n)$ as follows:

$$
d_{i j}=d\left(f_{j}^{*}, \tilde{x}_{i j}\right) / d\left(f_{j}^{*}, f_{j}^{-}\right)
$$

Step 8: Calculate $S_{i}$ and $R_{i}$ using the following equations:

$$
\begin{aligned}
& S_{i}=\sum_{j=1}^{n} w_{j}^{c} d_{i j} \\
& R_{i}=\max _{j}\left(w_{j}^{c} d_{i j}\right)
\end{aligned}
$$

Step 9: Compute $Q_{i}$ value (using Eq. 10). Initially, we set the value of parameter $v$ to 0.5 . Similarly, as in the case of parameter $\phi$, we later analyze the stability of ranking results changing the value of parameter $v$ in range $[0,1]$.
Step 10: Rank the alternatives in three descending lists (by values $S, R$ and $Q$ ).

Step 11: Propose a compromise solution.

The alternative $A^{\prime}$ which is the best ranked by the value $Q$ could be proposed as a compromise solution only if it satisfies the following conditions:

- Condition 1: The best ranked alternative $A$ ' must have the acceptable advantage over the second ranked alternative $A^{\prime \prime}$, i.e. $Q\left(A^{\prime \prime}\right)-Q\left(A^{\prime}\right) \geq D Q, D Q$ $=\min \{0.25,1 /(m-1)\}$ where $m$ stands for the number of alternatives.

- Condition 2: The alternative $A^{\prime}$ must also be the best ranked by values $S$ or $R$ making the compromise solution stabile in decision making.

Table 1 Importance weight of criteria assessed by decision makers

\begin{tabular}{llllllll}
\hline & $C_{1}$ & $C_{2}$ & $C_{3}$ & $C_{4}$ & $C_{5}$ & $C_{6}$ & $C_{7}$ \\
\hline$D M_{1}$ & $\mathrm{VH}$ & $\mathrm{H}$ & $\mathrm{H}$ & $\mathrm{VH}$ & $\mathrm{H}$ & $\mathrm{M}$ & $\mathrm{M}$ \\
$\mathrm{DM}_{2}$ & $\mathrm{H}$ & $\mathrm{VH}$ & $\mathrm{VH}$ & $\mathrm{M}$ & $\mathrm{VH}$ & $\mathrm{VH}$ & $\mathrm{L}$ \\
$\mathrm{DM}_{3}$ & $\mathrm{M}$ & $\mathrm{M}$ & $\mathrm{H}$ & $\mathrm{VL}$ & $\mathrm{M}$ & $\mathrm{L}$ & $\mathrm{VH}$ \\
\hline
\end{tabular}


If one of the conditions is not satisfied, the alternative $A^{\prime}$ together with the alternatives in closeness compound a set of compromise solutions. A set of compromise solutions includes:

- if Condition 1 is not satisfied: Alternatives $A^{\prime}, A^{\prime \prime}, \ldots$ $A^{(M)}$, where $A^{(M)}$ is obtained using the relation $Q\left(A^{(M)}\right)-Q\left(A^{\prime}\right)<D Q$.

- if only Condition 2 is not satisfied: Alternatives A and $A^{\prime \prime}$.

\section{An illustrative example}

To illustrate the use of the proposed approach to treat the evaluation problem at the early stage of an infrastructure project, a real-world application for the project of a railway line reconstruction is employed below. The proposed model is applied to find a compromise priority ranking of route alternatives for a regional railway line at Serbian network.

\subsection{Implementation of the proposed approach}

The illustrative example concerns the reconstruction of the regional railway line Pančevo - Vršac in a north-eastern district of Serbia. The observed line presents a part of an international route that links Belgrade, Serbian capital city with Timisoara, Romanian city. In the sense of developing the Comprehensive European Transport Network, this international route provides a connection between two core corridors: the Middle East - East Mediterranean Corridor and Rhine-Danube Corridor. The line Pančevo - Vršac is a single-track and non-electrified railway line. The line connects two large urban areas passing through a mostly rural area with a dozen of small towns and villages (Fig. 5). The length of the line is around $80 \mathrm{~km}$ and the alignment is relatively straight and flat. The line has not been reconstructed for last 30 years resulting in the poor infrastructure condition that hardly fulfils the requirements to run even the current rail traffic volume. In addition to the modernization in the sense of its electrification, it is necessary to investigate opportunities to upgrade the infrastructure and enhance rail service due to the expectation of the traffic volume increase on this international route (Step1).
Table 2 Rating of route alternatives with respect to criteria assessed by decision makers

\begin{tabular}{cccccccc}
\hline & $C_{1}$ & $C_{2}$ & $C_{3}$ & $C_{4}$ & $C_{5}$ & $C_{6}$ & $C_{7}$ \\
\hline$D M_{1}$ & & & & & & & \\
$A_{0}$ & $P$ & $V P$ & $V P$ & $G$ & $P$ & $P$ & $P$ \\
$A_{1}$ & $V G$ & $P$ & $P$ & $V G$ & $V P$ & $G$ & $P$ \\
$A_{2}$ & $F$ & $G$ & $F$ & $G$ & $G$ & $F$ & $P$ \\
$A_{3}$ & $V P$ & $V G$ & $V G$ & $V P$ & $F$ & $V G$ & $V P$ \\
$D M_{2}$ & & & & & & & \\
$A_{0}$ & $P$ & $V P$ & $P$ & $G$ & $P$ & $V P$ & $P$ \\
$A_{1}$ & $V G$ & $P$ & $P$ & $G$ & $P$ & $P$ & $G$ \\
$A_{2}$ & $G$ & $G$ & $G$ & $F$ & $V G$ & $G$ & $F$ \\
$A_{3}$ & $F$ & $V G$ & $V G$ & $P$ & $G$ & $V G$ & $P$ \\
$D M_{3}$ & & & & & & & \\
$A_{0}$ & $F$ & $P$ & $F$ & $G$ & $P$ & $P$ & $V P$ \\
$A_{1}$ & $G$ & $F$ & $G$ & $G$ & $P$ & $F$ & $G$ \\
$A_{2}$ & $G$ & $G$ & $F$ & $G$ & $G$ & $G$ & $P$ \\
$A_{3}$ & $P$ & $G$ & $P$ & $P$ & $G$ & $G$ & $V P$ \\
\hline & & & & & & &
\end{tabular}

Afterwards, a committee of experts is formed to act as decision makers in selecting the most suitable railway line reconstruction alternative. The committee is established including three experts, $D M_{1}, D M_{2}$ and $D M_{3}$, from various professional fields. Specifically, $D M_{1}$ contributes the expertise in railway structures and alignment design, $\mathrm{DM}_{2}$ contributes the expertise in railway operation and transport economics, and finally $D M_{3}$ contributes the expertise in spatial planning and environmental protection. A set of 7 criteria is adopted to perform evaluation of the reconstruction alternatives encompassing: financial requirements $\left(C_{1}\right)$, rail service quality $\left(C_{2}\right)$, safety performance $\left(C_{3}\right)$, project risks $\left(C_{4}\right)$, transport politics $\left(C_{5}\right)$, economic effects $\left(C_{6}\right)$ and environmental impacts $\left(C_{7}\right)$. The assessment of financial requirements refers to the calculations of initial investments, maintenance and operation costs for each alternative. From the aspect of rail service, vital quality indicators refer to the line capacity, timetable stability, travel time and convenience. The safety performance among route alternatives mainly depends on the number of rail-road grade crossings and their equipment. Also, the safety performance concerns the potential of unauthorized person fatalities

Table 3 Aggregated fuzzy ratings of route alternatives and subjective fuzzy weights of criteria

\begin{tabular}{llllllll}
\hline & $C_{1}$ & $C_{2}$ & $C_{3}$ & $C_{4}$ & $C_{5}$ & $C_{6}$ & $C_{7}$ \\
\hline$w_{j}^{5}$ & $(0.25,0.75,1)$ & $(0.25,0.75,1)$ & $(0.50,0.83,1)$ & $(0,0.50,1)$ & $(0.25,0.75,1)$ & $(0,0.58,1)$ & $(0,0.58,1)$ \\
$A_{0}$ & $(0,0.33,0.75)$ & $(0,0.08,0.50)$ & $(0,0.25,0.75)$ & $(0.50,0.75,1)$ & $(0,0.25,0.50)$ & $(0,0.17,0.50)$ & $(0,0.17,0.50)$ \\
$A_{1}$ & $(0.50,0.92,1)$ & $(0,0.33,0.75)$ & $(0,0.42,1)$ & $(0.5,0.83,1)$ & $(0,0.17,0.50)$ & $(0,0.50,1)$ & $(0,0.58,1)$ \\
$A_{2}$ & $(0.25,0.67,1)$ & $(0.50,0.75,1)$ & $(0.25,0.58,1)$ & $(0.25,0.67,1)$ & $(0.50,0.83,1)$ & $(0.25,0.67,1)$ & $(0,0.33,0.75)$ \\
$A_{3}$ & $(0,0.25,0.75)$ & $(0.50,0.92,1)$ & $(0,0.75,1)$ & $(0,0.17,0.5)$ & $(0.25,0.67,1)$ & $(0.5,0.92,1)$ & $(0,0.08,0.5)$ \\
\hline
\end{tabular}


that rises as train running speed increases. Foreseen potential delays and cost overruns are considered under the risks for project realization and compared among alternatives. In addition, the evaluation considers the consistency of alternatives with regional and national transport and infrastructure development strategies and the compliance with external projects on developing railway transport on this route. Economic effects are represented by the ability to increase direct revenues from track access charges and to enhance regional economic competitiveness level directly or indirectly by each railway line reconstruction alternative. Finally, spatial structure transformations and ecological consequences are considered as environmental impacts.

After the preliminary screening, three draft railway route alternatives were designed within the corridor of existing railway line and further evaluated in comparison with "do nothing" alternative. In the "do nothing" alternative, no changes would be made to the route alignment and rail traffic keeps operating in actual state, without adaptation. Due to the current poor state of railway infrastructure, trains runs at reduced speed. In several parts of the railway line, rail substructure is in such a poor condition that the speed is reduced below $100 \mathrm{~km} / \mathrm{h}$. Rail traffic operates in the simplest form so that only one train runs between two adjacent stations. The line has numerous rail-road crossings mainly unequipped with safety devices.

The first alternative $\left(A_{1}\right)$ rehabilitates the railway route back to the originally designed state permitting train running up to $100 \mathrm{~km} / \mathrm{h}$. Its length and basic components of alignment do not change comparing to the current state. Returning the infrastructure to the originally designed state creates the base for reliable and punctual rail service. Rail traffic keeps operating with single block sections between two adjacent stations. The number of rail-road crossings is decreased closing all unauthorized crossings and some crossings at field roads. The alternative proposes setting all remaining rail-road grade crossings equipped with signs and some kind of safety devices.

The second alternative $\left(A_{2}\right)$ reconstructs the railway route permitting train running up to $120 \mathrm{~km} / \mathrm{h}$. The route mainly follows the existing line and its length is around $85 \mathrm{~km}$. Comparing to the current route the alignment is stretched replacing a number of small curves with curves of minimum radius of $700 \mathrm{~m}$. Rail traffic operation is improved introducing multiple block
Table 4 Combination weights of criteria

\begin{tabular}{lccccccc}
\hline & $C_{1}$ & $C_{2}$ & $C_{3}$ & $C_{4}$ & $C_{5}$ & $C_{6}$ & $C_{7}$ \\
\hline Subj. weights $\left(W_{j}^{5}\right)$ & & & & & & & \\
$\quad \begin{array}{l}\text { Defuzzified } \\
\quad \text { Normalized }\end{array}$ & 0.67 & 0.67 & 0.78 & 0.50 & 0.67 & 0.53 & 0.13 \\
Obj. weights $\left(W_{j}^{\circ}\right)$ & & 0.15 & 0.18 & 0.12 & 0.15 & 0.12 & 0.12 \\
$e_{j}$ & 0.95 & 0.91 & 0.98 & 0.94 & 0.90 & 0.94 & 0.94 \\
$\quad d i v_{j}$ & 0.05 & 0.09 & 0.02 & 0.06 & 0.10 & 0.06 & 0.06 \\
$\quad$ Normalized & 0.11 & 0.21 & 0.04 & 0.14 & 0.22 & 0.14 & 0.13 \\
Comb. weights $\left(W_{j}^{c}\right)$ & 0.13 & 0.18 & 0.11 & 0.13 & 0.19 & 0.13 & 0.13 \\
\hline
\end{tabular}

sections which permit more than one train to run in the same direction between two adjacent stations. The number of rail-road crossings is reduced in the sense that large grade crossings in urban areas are grade separated and that crossings in the rural areas are consolidated. The alternative proposes setting all remaining rail-road grade crossings equipped with barriers and alarms as active traffic control devices.

The third alternative $\left(A_{3}\right)$ reconstructs the railway route permitting train running up to $160 \mathrm{~km} / \mathrm{h}$. The route partly follows the existing line and its length is around $80 \mathrm{~km}$. Comparing to the current route, the alignment is more straight reducing the number of curves and applying larger radius (curves of minimum radius of $1500 \mathrm{~m}$ ). In addition to the application of multiple block sections rail traffic operation is improved introducing a few double track sections permitting trains running in opposite directions concurrently. The alternative proposes setting all rail-road crossings as grade separated.

Each decision maker uses linguistic variables shown in Figs. 2 and 3 to assign the weights of evaluation criteria and ratings of reconstruction alternatives. The linguistic terms provided by decision makers to weight criteria and ratings of alternatives are shown in Table 1 and Table 2 (Step 3).

The linguistic weighting and rating terms shown in Tables 1 and 2 are transformed into triangular fuzzy numbers. The fuzzy numbers are aggregated deriving subjective fuzzy weights of criteria and fuzzy ratings of alternatives concerning each criterion as in Table 3 (Step 4). Afterwards, the values from fuzzy decision making matrix are defuzzified using Eq. (2).

Table 4 shows weighting of the criteria (Step 5). The subjective weights are normalized using Eq. (12) while

Table 5 Calculated $f_{j}^{*}$ and $f_{j}^{-}$for each criterion

\begin{tabular}{llllllll}
\hline & $C_{1}$ & $C_{2}$ & $C_{3}$ & $C_{4}$ & $C_{5}$ & $C_{6}$ & $C_{7}$ \\
\hline$f_{j}^{*}$ & $(0.50,0.92,1)$ & $(0.50,0.92,1)$ & $(0.25,0.58,1)$ & $(0.50,0.83,1)$ & $(0.50,0.83,1)$ & $(0.50,0.92,1)$ & $(0,0.58,1)$ \\
$f_{j}^{-}$ & $(0,0.25,0.75)$ & $(0,0.08,0.50)$ & $(0,0.25,0.75)$ & $(0,0.17,0.50)$ & $(0,0.17,0.50)$ & $(0,0.17,0.50)$ & $(0,0.08,0.50)$ \\
\hline
\end{tabular}


Table 6 Normalized fuzzy distances of alternatives

\begin{tabular}{llllllll}
\hline & $C_{1}$ & $C_{2}$ & $C_{3}$ & $C_{4}$ & $C_{5}$ & $C_{6}$ & $C_{7}$ \\
\hline$d\left(f j^{*}-f_{j}^{-}\right)$ & 0.93 & 1.00 & 1.00 & 0.09 & 0.94 & 1.00 & 0.92 \\
$d\left(f j^{*}-A_{0}\right)$ & 0.00 & 0.74 & 0.62 & 0.00 & 1.00 & 0.63 & 0.00 \\
$d\left(f f^{*}-A_{1}\right)$ & 0.41 & 0.15 & 0.00 & 0.31 & 0.00 & 0.34 & 0.50 \\
$d\left(f j^{*}-A_{2}\right)$ & 1.00 & 0.00 & 0.62 & 1.00 & 0.31 & 0.00 & 1.00 \\
$d\left(f^{*}-A_{3}\right)$ & 0.93 & 1.00 & 1.00 & 0.09 & 0.94 & 1.00 & 0.92 \\
\hline
\end{tabular}

the objective weights are derived using entropy calculations Eq.(3) - Eq. (6). Consequently, the combination weights are calculated using Eq. (13).

The following steps determine extreme values among alternatives for each criterion (Step 6) and normalize fuzzy distances of alternatives (Step 7). The fuzzy best and fuzzy worst values among aggregated ratings of alternatives are derived using Eq. (15) and Eq. (16) as in Table 5. Table 6 shows the normalized fuzzy distance calculated using Eq. (17).

Finally, the values $S, R$ and $Q$ are derived for all reconstruction alternatives as in Table 7 (Step 8 and Step 9). Priority orders of alternative routes by $S, R$ and $Q$ are shown in Table 8 (Step 10). The alternative route $A_{2}$ is the best ranked alternative by the value $Q$ and could be proposed for the compromise solution due to the satisfaction of additional conditions (Step 11):

- Condition 1: $Q\left(A_{2}\right)-Q\left(A_{1}\right)=0.6$ which is higher than $D Q(D Q=0.25)$ and

- Condition 2: the alternative $A_{2}$ is the best ranked by the measures $S$ and $R$ also.

\subsection{Result discussions}

The ranking results in Table 8 indicate that all three reconstruction alternatives are superior over the "do nothing" alternative. The alternative $A_{2}$ is the best ranked and it is proposed as a base for further project development and detailed evaluations. The alternative $A_{2}$ presents a real compromise solution over proposed alternatives concerning benefits in service quality, safety performances and economics against financial requirements, project risks and environmental impacts. In addition, the alternative $A_{2}$ is superior over another two reconstruction alternatives concerning actual transport politics. Actually, the alternative is consistent with Balkans regional infrastructure network development plans and Serbian railway rehabilitation program. The

Table 7 Values of $S, R$ and $Q$ for all alternatives

\begin{tabular}{lllll}
\hline & $A_{0}$ & $A_{1}$ & $A_{2}$ & $A_{3}$ \\
\hline$S_{i}$ & 0.85 & 0.48 & 0.23 & 0.51 \\
$R_{i}$ & 0.18 & 0.19 & 0.06 & 0.13 \\
$Q_{i}$ & 0.98 & 0.70 & 0 & 0.50 \\
\hline
\end{tabular}

Table 8 Ranking of alternatives by $S, R$ and $Q$

\begin{tabular}{lllll}
\hline & $A_{0}$ & $A_{1}$ & $A_{2}$ & $A_{3}$ \\
\hline$S_{i}$ & 4 & 2 & 1 & 3 \\
$R_{i}$ & 3 & 4 & 1 & 2 \\
$Q_{i}$ & 4 & 3 & 1 & 2 \\
\hline
\end{tabular}

program includes the reconstruction of the adjacent section on this route between Belgrade and Pančevo for speeds of $120 \mathrm{~km} / \mathrm{h}$ and the modernization of rolling stock with a new generation of electric multiple units for regional transport.

Furthermore, we discuss ranking results considering different visions of committee experts. Under a GDM process, experts are characterized not only by heterogeneous, but even conflicting evaluations of decision making attributes (criteria and alternatives). Conflicts between two committee experts arise due to differences in perspectives and capabilities in evaluating the attributes. Different decision makers have different priorities for the criteria assessment and they have their own opinions on the influence of some criteria on the alternatives. The differences in evaluating the railway route alternatives over the experts are shown in Tables 1 and 2 . Table 9 shows the ranking of alternatives extracting the individual expertise of the decision makers. It can be seen that priority rankings by the measure $Q$ obtained considering individual DMs judgments differ from results of the base scenario in the Table 8 .

Considering the individual $D M_{1}$ judgment, the alternative $\mathrm{A}_{2}$ remains the best ranked but other two reconstruction alternatives switch rank positions prioritizing lower financial requirements and project risks. Considering the individual judgment of $D M_{2}$ priorities are given to service quality, safety performances, transport politics and economic effects. The base ranking list remains with the difference that the alternative $\mathrm{A}_{2}$ has only a slight advantage over the alternative $A_{3}$. From his perspective, both alternatives should be proposed as a set of compromise solutions. Finally, the ranking list of the reconstruction alternatives has fully changed when considering the individual $\mathrm{DM}_{3}$ judgment. Although all three reconstruction alternatives bring grate benefits from the railway line electrification in terms of environmental impact, the influences over spatial structures and ecological consequences rise over alternatives as running

Table 9 Ranking of alternatives by each decision maker

\begin{tabular}{|c|c|c|c|c|}
\hline & \multicolumn{4}{|c|}{ Ranking } \\
\hline & 1 & 2 & 3 & 4 \\
\hline by $D M_{1}$ & $A_{2}$ & $A_{1}$ & $A_{3}$ & $A_{0}$ \\
\hline by $D M_{2}$ & $A_{2}$ & $A_{3}$ & $A_{1}$ & $A_{0}$ \\
\hline by $D M_{3}$ & $A_{1}$ & $A_{2}$ & $A_{3}$ & $A_{O}$ \\
\hline
\end{tabular}




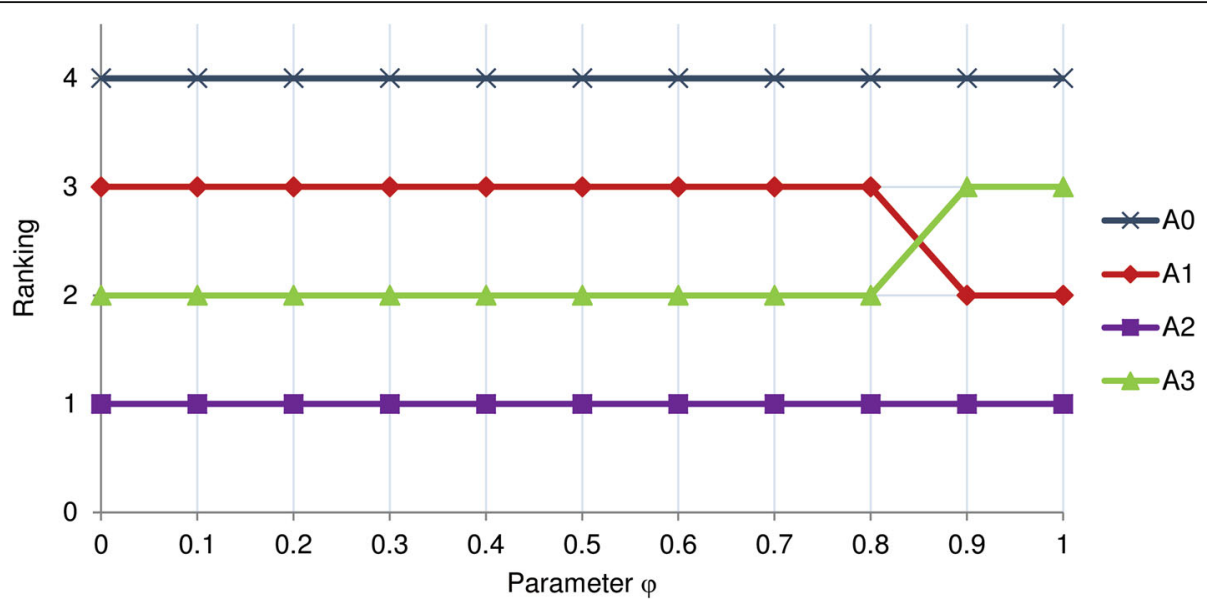

Fig. 6 Sensitivity analysis of the $\varphi$ value

speed increase. Also the increase in speed is viewed as a negative phenomenon due to the potential of unauthorized person fatalities in urban areas and train-animal collisions in rural areas. Therefore, the alternative $A_{1}$ is assigned as the best ranked in terms of the $D M_{3}$ judgment.

\subsection{Sensitivity analysis}

In addition, we consider the stability of ranking results considering changes in the values of parameters $\phi$ and $v$ that play important roles in the ranking procedure. The parameter $\phi$ reflects a balance between subjective and objective weightings. Figure 6 shows priority ranking comparisons considering different values of the weight parameter $\phi$ from 0 to 1 . The ranking orders of the proposed reconstruction alternatives are slightly influenced so that the best ranked alternative is not affected while other two alternatives $\left(A_{1}\right.$ and $\left.A_{3}\right)$ switch ranking positions when considering more objective weighting ( $\phi$ equal of higher then 0.9 ).
Furthermore, the related results according to the sensitivity analysis of the parameter $v$ are illustrated in the Fig. 7. The parameter $v$ reflects a balance between two strategies: a maximum group utility and a minimum of individual regret of the opponent. The results show that the best ranked alternative is the same in terms of both strategies and satisfies the condition of the acceptable advantage over the entire interval $v=[0,1]$ while some changes appear in ranking other alternatives. In terms of a minimum individual regret of the opponent ( $v$ equal to 0 ), the alternative $A_{1}$ is the lowest ranked alternative falling even below the alternative $A_{0}$ ("do nothing" alternative). When considering a maximum group utility to be more important ( $v$ equal or higher then 0.9 ), alternatives $A_{1}$ and $A_{3}$ switch ranking positions while $A_{0}$ remains the lowest ranked alternative.

\section{Conclusions}

Although imposing high financial requirements, transportation infrastructure projects intend to stimulate

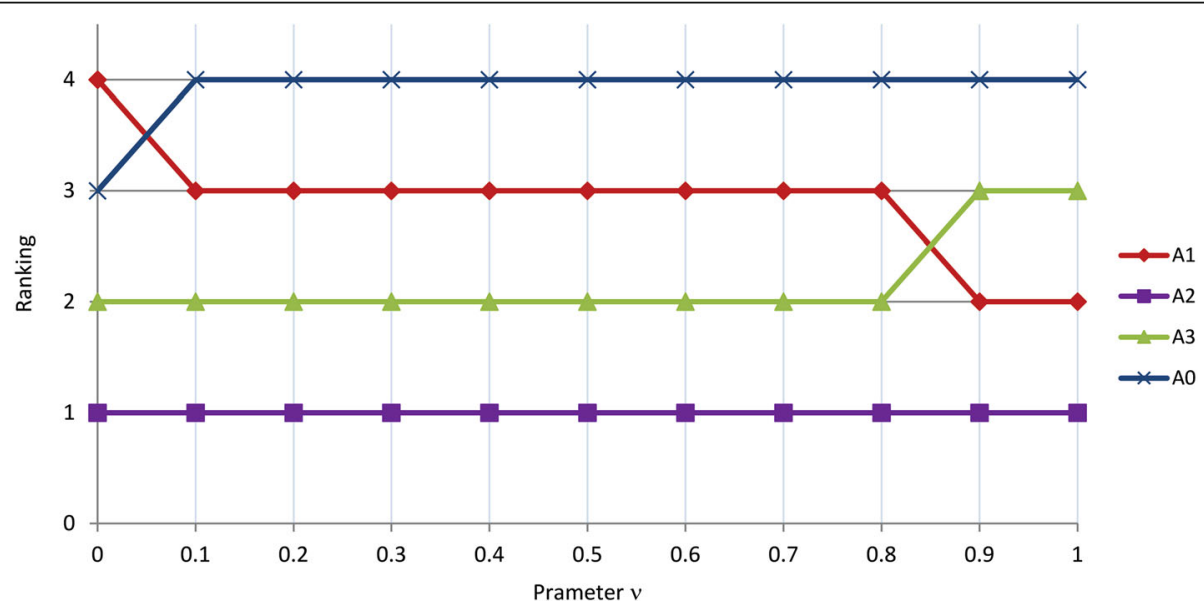

Fig. 7 Sensitivity analysis of the $v$ value 
economic growth, employment and a rising standard of living in regions, nations and internationally. The evaluation and selection of transportation infrastructure projects is a complicated process that involves a variety of aspects encompassing structural and operational design, project economics, risks and impacts. The assessment of project alternatives incorporating all these aspects is required to perform a proper decision making at the stage of planning and design of the infrastructure. In this paper, we focused on the evaluations of project alternatives at the early stage of an infrastructure project development. Although early stage evaluations are essential to utilize the project resources effectively, they are often influenced by low quality data and other uncertainties in practice. Actually, decision makers are unable to express their opinions precisely and they often make evaluations using linguistic terms. This makes fuzzy set theory a suitable approach to handle this kind of problems. Moreover, the fuzzy approach was chosen because it can handle criteria with both qualitative and quantitative aspects which are judged upon decision maker expertise involving vagueness and ambiguity.

In this paper, the evaluation methodology utilized combination weighting and fuzzy VIKOR method to treat the railway route reconstruction problem and to identify the most suitable route alternative. In order to determine criteria weights, we integrated the subjective and objective weighting methods. Subjective weights were aggregated from surveys of decision makers and objective weights were derived applying the entropy-based method. The ranking of route alternatives and selection of the most suitable one were performed applying the VIKOR method extended under fuzzy environment. The obtained compromise solution is stabile both in terms of a maximum group utility and a minimum of the individual regret of the opponent.

The provided example illustrates the applicability of the proposed approach to deal with the evaluation problem at the early stage of a railway line reconstruction project. Furthermore, considerations on individual judgments of decision makers validated the reliability of the method. Besides, the sensitivity analysis pointed out the stability of ranking results to parameters' changes. The proposed method could be applied for various linear infrastructure projects in transport sector. The method could be adopted in ranking alternatives among the same base project as well as in ranking various projects across a portfolio.

Future research could address the following directions. Firstly, the application of other available approaches should be considered for aggregating group preferences over decision making attributes. Evidential reasoning presents an approach that can preserve uncertainties embedded in individual judgments of decision makers as independent sources of evidence. It would be valuable to address this approach in the sense of treating incomplete or conflicting data provided by different decision makers as experts from heterogeneous professional fields. Moreover, further research should consider differentiating the competence of different evidences. The competence of individual decision makers was not considered in the proposed method. In some situations, it is justified to introduce weights of the competence associated with different decision makers involved in the project evaluation. Finally, further research could also address the problem of deriving parameters $\phi$ and $v$ objectively, as two influential parameters that act on the final ranking.

\section{Funding}

The paper is supported by "Ministy of Education, Science and Technological Development of the Republic of Serbia (Grant TR36012)".

Authors' contributions

All authors read and approved the final manuscript.

Competing interests

The authors declare that they have no competing interests.

\section{Publisher's Note}

Springer Nature remains neutral with regard to jurisdictional claims in published maps and institutional affiliations.

Received: 8 November 2017 Accepted: 18 September 2018

Published online: 28 September 2018

\section{References}

1. Kalamaras GS, Brino L, Carrieri G, Pline C, Grasso P (2000) Application of multicriteria analysis to select the best highway alignment. Tunn Undergr Space Technol 15(4):415-420

2. Kosijer M, Ivic M, Markovic M, Belosevic I (2012) Multicriteria decisionmaking in railway route planning and design. Gradevinar 64(3):195-205

3. Sperry B, Mueller J, Hunter-Zaworski K (2013) Development of multicriteria decision method for evaluating high-speed rail corridor. Transp Res Rec: J Transp Res Board 2374:26-34

4. Wang TC, Lee HD (2009) Developing a fuzzy TOPSIS approach based on subjective weights and objective weights. Expert Syst Appl 36(5):8980-8985

5. Liu H-C, You J-X, You X-Y, Shan M-M (2015) A novel approach for failure mode and effects analysis using combination weighting and fuzzy VIKOR method. Appl Soft Comput 28:579-588

6. Feizi F, Karbalaei-Ramezanali A, Tusi H (2017) Mineral potential mapping via TOPSIS with hybrid AHP-Shannon entropy weighting of evidence: a case study for porphyry-cu, Farmahin area, Markazi Province, Iran. Nat Resour Res 26(4):553-570. https://doi.org/10.1007/s11053-017-9338-3

7. Karleuša B, Dragičević N, Deluka-Tibljaš A (2013) Review of multicriteriaanalysis methods application in decision making about transport infrastructure. Gradevinar 65(7):619-631

8. Kabir G, Sadiq R, Tesfamariam S (2014) A review of multi-criteria decisionmaking methods for infrastructure management. Struct Infrastruct Eng 10(9):1176-1210

9. Zavadskas EK, Antuchevičienė J, Kapliński O (2015) Multi-criteria decision making in civil engineering: part I - a state of the art survey. Eng Struct Technol 7(3):103-113

10. Zavadskas EK, Antuchevičienė J, Kapliński O (2015) Multi-criteria decision making in civil engineering. Part II - applications. Eng Struct Technol 7(4): $151-167$

11. Banai R (2006) Public transportation decision-making: a case analysis of the Memphis light rail corridor and route selection with analytic hierarchy process. J Public Transp 9(2):1-24

12. Banai R (2010) Evaluation of land use-transportation systems with the analytic network process. J Transp Land Use 3(1):85-112 
13. Ballestero E, Manuel AJ, Bielza C (2003) Compromise-based approach to road project selection in Madrid metropolitan area. J Oper Res Soc Jpn 46(1):99-122

14. Anton JM, Grau JB (2004) Madrid-Valencia high-speed rail line: a route selection. Proc Inst Civ Eng - Transp 157(3):153-161

15. Saat MR, Aguilar Serrano J (2015) Multicriteria high-speed rail route selection: application to Malaysia's high-speed rail corridor prioritization. Transp Plan Technol 38(2):200-213

16. Delle Site P, Filippi F (2009) Weighting methods in multi-attribute assessment of transport projects. Eur Transp Res Rev 1(4):199-206

17. Brauers WKM, Zavadskas EK, Peldschus F, Turskis Z (2008) Multi-objective decision-making for road design. Transport 23(3):183-193

18. Barić D, Pilko H, Strujić J (2016) An analytic hierarchy process model to evaluate road section design. Transport 31(3):312-321

19. Sarrazin $R$, De Smet $Y$ (2015) Applying multicriteria decision analysis to design safe road projects. Eur J Transp Infrastruct Res 15(4):613-634

20. Basile O, Persia L, Usami DS (2010) A methodology to assess pedestrian crossing safety. Eur Transp Res Rev 2(3):129-137

21. Wiethoff M, Brookhuis K, de Waard D, Marchau V, Walta L, Wenzel G, de Brucker K, Macharis C (2012) A methodology for improving road safety by novel infrastructural and invehicle technology combinations. Eur Transp Res Rev 4(2):67-77

22. Ait-Mlouk A, Gharnati F, Agouti T (2017) An improved approach for association rule mining using a multi-criteria decision support system: a case study in road safety. Eur Transp Res Rev 9(3):40

23. Zadeh LA (1965) Fuzzy sets. Inf Control 8(3):338-353

24. Bellman RE, Zadeh LA (1970) Decision-making in a fuzzy environment. Manag Sci 17(4):B141-B164

25. Mardani A, Jusoh A, Zavadskas EK (2015) Fuzzy multiple criteria decisionmaking techniques and applications - two decades review from 1994 to 2014. Expert Syst Appl 42(8):4126-4148

26. Shafabakhsh G, Hadjihoseinlou M, Taghizadeh SA (2014) Selecting the appropriate public transportation system to access the Sari International airport by fuzzy decision making. Eur Transp Res Rev 6(3):277-285

27. Gajzler M, Zima K (2017) Evaluation of planned construction projects using fuzzy logic. Int J Civil Eng 15(4):641-652

28. Cheng C-H, Lin Y (2002) Evaluating the best main battle tank using fuzzy decision theory with linguistic criteria evaluation. Eur J Oper Res 142(1):174186 doi:https://doi.org/10.1016/S0377-2217(01)00280-6

29. Chen LY, Wang T-C (2009) Optimizing partners' choice in IS/IT outsourcing projects: the strategic decision of fuzzy VIKOR. Int J Prod Econ 120(1):233242 doi:https://doi.org/10.1016/j.jpe.2008.07.022

30. Kaufmann A, Gupta MM (1985) Introduction to fuzzy arithmetic: theory and applications. Van Nostrand Reinhold, New York

31. Zimmermann HJ (2011) Fuzzy set theory - and its applications. Springer Science \& Business Media, New York

32. Chen CT (2000) Extensions of the TOPSIS for group decision-making under fuzzy environment. Fuzzy Sets Syst 114(1):1-9

33. Mohsen O, Fereshteh N (2017) An extended VIKOR method based on entropy measure for the failure modes risk assessment - a case study of the geothermal power plant (GPP). Saf Sci 92(Supplement C):160-172 doi: https://doi.org/10.1016/j.ssci.2016.10.006

34. Shemshadi A, Shirazi H, Toreihi M, Tarokh MJ (2011) A fuzzy VIKOR method for supplier selection based on entropy measure for objective weighting. Expert Syst Appl 38(10):12160-12167

35. Shannon C, Weaver W (1964) The mathematical theory of communication, 10th edn. The University of Illinois Press, Urban

36. Opricovic S (1998) Multicriteria optimization of civil engineering systems. Faculty of Civil Engineering, Belgrade

37. Opricovic S (2011) Fuzzy VIKOR with an application to water resources planning. Expert Syst Appl 38(10):12983-12990

38. Opricovic S, Tzeng GH (2004) Compromise solution by MCDM methods: a comparative analysis of VIKOR and TOPSIS. Eur J Oper Res 156(2):445-455

39. Opricovic S, Tzeng GH (2007) Extended VIKOR method in comparison with outranking methods. Eur J Oper Res 178(2):514-529

40. Gul M, Celik E, Aydin N, Taskin Gumus A, Guneri AF (2016) A state of the art literature review of VIKOR and its fuzzy extensions on applications. Appl Soft Comput 46:60-89

41. Mardani A, Zavadskas E, Govindan K, Amat Senin A, Jusoh A (2016) VIKOR technique: a systematic review of the state of the art literature on methodologies and applications. Sustainability 8(1):37
42. Yu PL (1973) A class of solutions for group decision problems. Manag Sci 19(8):936-946

43. Zeleny M (1982) Multiple criteria decision making. Mc Graw-Hill, New York

44. Ringuest JL (1992) Compromise programming. In: Ringuest JL (ed) Multiobjective optimization: behavioral and computational considerations. Springer US, Boston, pp 51-59. https://doi.org/10.1007/978-1-4615-3612-3_4

45. Liu H-C (2016) FMEA using uncertainty theories and MCDM methods. In: Liu H$C$ (ed) FMEA using uncertainty theories and MCDM methods. Springer Singapore, Singapore, pp 13-27. https://doi.org/10.1007/978-981-10-1466-6_2

46. Yücenur GN, Demirel NÇ (2012) Group decision making process for insurance company selection problem with extended VIKOR method under fuzzy environment. Expert Syst Appl 39(3):3702-3707 doi:https://doi.org/10. 1016/j.eswa.2011.09.065

47. Sanayei A, Farid Mousavi S, Yazdankhah A (2010) Group decision making process for supplier selection with VIKOR under fuzzy environment. Expert Syst Appl 37(1):24-30 doi:https://doi.org/10.1016/j.eswa.2009.04.063

\section{Submit your manuscript to a SpringerOpen ${ }^{\circ}$ journal and benefit from:}

- Convenient online submission

- Rigorous peer review

- Open access: articles freely available online

- High visibility within the field

- Retaining the copyright to your article

Submit your next manuscript at $>$ springeropen.com 